Flashlamp Pumped, ROom Temperature, Nd:YAG Laser

Operating at 0.946 micrometers

\author{
Norman P. Barnes \\ Keith E. Murray \\ NASA Langley Research Center \\ M/S 474 \\ Hampton, VA 23681 \\ (757) $864-1630$ \\ FAX (757) 864-8809 \\ Brian M. Walsh \\ Boston College \\ Department of Physics \\ Chestnut Hill, MA 02167
}

\begin{abstract}
Room temperature operation of flashlamp pumped Nd:YAG at 0.946 $\mu \mathrm{m}$ was achieved with a laser rod having undoped ends. Performance was characterized and compared with $1.064 \mu \mathrm{m}$ operation and other quasi four level lasers.
\end{abstract}




\title{
Flashlamp Pumped, Room Temperature, Nd:YAG Laser operating at 0.946 micrometers
}

\author{
Norman P. Barnes \\ Keith E. Murray \\ NASA Langley Research Center \\ Hampton, VA 23681 \\ Brian M. Walsh \\ Boston College \\ Chestnut Hill, MA 02167
}

A flashlamp pumped, room temperature, Nd:YAG laser operating at $0.946 \mu \mathrm{m}$ with a threshold of $16.8 \mathrm{~J}$ and a slope efficiency of 0.0032 has been achieved. To date, flashlamp pumped operation of Nd:YAG on the $0.946 \mu \mathrm{m}$ transition has often been 1 imited to reduced temperatures and modest efficiencies [1]. Modest performance is often ascribed to its quasi four level nature. However, it is shown here that laser is also limited by the competing $1.064 \mu \mathrm{m}$ transition. These effects are mitigated through careful design, including the use of undoped YAG ends bonded onto the laser rod. An analysis of the laser, including a novel approach to describing the effect of the competing transitions, demonstrates that most standard laser rod designs are not conducive to good performance at $0.946 \mu \mathrm{m}$. However, with attention to the design, performance competitive with the performance at $1.064 \mu \mathrm{m}$ is possible.

Quasi four level operation and a relatively small stimulated emission cross section by themselves do not preclude the Nd:YAG laser from operating efficiently at $0.946 \mu \mathrm{m}$. A table comparing the Nd:YAG laser operating at $0.946 \mu \mathrm{m}$ with another quasi four level laser, Ho:Tm:Er:YLF, appears below.

$\begin{array}{lllll}\text { Wavelength } & 0.946 & 1.064 & 2.051 & \mu \mathrm{m} \\ \text { Material } & \text { Nd:YAG } & \text { Nd:YAG } & \text { Ho:Tm: Er:YLF } & \\ \text { Thermal occupation } & & \\ \text { Upper } & 0.60 & 0.40 & 0.0874 \\ \text { Lower } & 0.0072 & 0 & 0.0286 \\ \text { Transparency } & 0.012 & 0 & 0.25 & \\ \text { Cross Section } & 3.7 & 34.0 & 1.8 & 10^{-24} \mathrm{~m}^{2}\end{array}$

Using the thermal occupation factors or Boltzmann factors of the upper and lower laser levels for the two laser materials, only 0.012 of the Nd atoms must be excited to the upper laser manifold to overcome the thermal population in the lower laser level, that is to achieve optical transparency. On the other hand, 0.25 of the Ho atoms are required for optical transparency. In addition, the emission cross section of Ho:Tm:Er:YLF laser is a factor of two smaller than that of the $0.946 \mu \mathrm{m}$ transition. Yet the flashlamp pumped Ho:Tm: Er:YLF laser operates efficiently at room temperature [2]. The additional effect which must be taken into account with the $0.946 \mu \mathrm{m}$ Nd:YAG laser is the high gain on the competing 1.064 $\mu \mathrm{m}$ transition. A gain of $\exp (1)$ at $0.946 \mu \mathrm{m}$ implies a gain of 
$\exp (10)$ at $1.064 \mu \mathrm{m}$.

Gain measurements of the flashlamp pumped Nd:YAG laser confirmed the effects associated with the high gain at $1.064 \mu \mathrm{m}$. Gain at $1.064 \mu \mathrm{m}$ is plotted versus pump energy in Figure 1 . Gain does not increase linearly with pump energy, rather it tends to saturate at a value between about 3.0 and 4.0 , depending on the particular laser design. Again depending on the laser design, this level of inversion may not be enough to even achieve optical transparency. To increase the level of inversion for the $0.946 \mu \mathrm{m}$ transition without exceeding the gain limit set by the competing $1.064 \mu \mathrm{m}$ transition, the laser rod was kept short and undoped YAG ends were bonded onto the ends to minimize any unpumped volume.

Decay of the inversion can be well described using a novel approach to the generalized amplified spontaneous emission, the addition of a quadratic loss term. An advantage of this approach is that the resulting differential equation can be solved in closed form and the parameters can be readily physically identified. Decay of the upper laser level is shown in Figure 2 where the nonexponential behavior of the decay is observable at high gain levels. A curve fit of the solution to the differential equation to the data yields a line which is nearly indistinguishable from the measured curve, as shown in the Figure.

Using the short laser rod with undoped YAG ends, a flashlamp pumped Nd:YAG laser was characterized both at 0.946 and $1.064 \mu \mathrm{m}$ as a function for various output mirrors and operating temperatures. A folded resonator, with a folding mirror highly transparent at $1.064 \mu \mathrm{m}$, was used for discrimination. By plotting the slope efficiency as a function of the mirror reflectivity, it was determined that the losses at $0.946 \mu \mathrm{m}$ were quite large. This is due primarily to the antireflection coatings on the laser rod which were centered so as to avoid parasitic lasing at $1.064 \mu \mathrm{m}$.

A flashlamp pumped, room temperature, Nd:YAG laser produced a threshold of $16.8 \mathrm{~J}$ and a slope efficiency of 0.0032 when operated at $0.946 \mu \mathrm{m}$. When operated at 1.064 , this laser produced a slope efficiency of 0.025 . Differences in the slope efficiencies can be attributed to several effects including: increased losses at 0.946 $\mu \mathrm{m}$, smaller beam radius, increased fluorescent losses due to amplified spontaneous emission, and less efficient pumping due to a blue shift in the lamp output spectrum. These effects have been evaluated and their cumulative effect accounts for the difference in the observed slope efficiencies.

1. S. Dimov, E. Peik and H. Walther, "A Flashlamp Pumped $946 \mathrm{~nm}$ Nd:YAG Laser," Appl. Phys. B, 53, 6-10 (1991) A threshold of about $62 \mathrm{~J}$ and a slope efficiency of 0.0014 was reported at $248^{\circ} \mathrm{K}$.

2. E. P. Chicklis, C. S. Naiman, R. C. Folweiler, and J. C. Doherty, "stimulated Emission In Multiply Doped Ho:YLF And YAG, A Comparison," IEEE J. Quant. Elect. QE-8 225-230 (1972) A threshold of about $42 \mathrm{~J}$ and a slope efficiency of 0.0075 was reported. 


\section{Gain of Nd:YAG at 1.064 Micrometers \\ 5.0 by $38.0 \mathrm{~mm}$ laser rod}

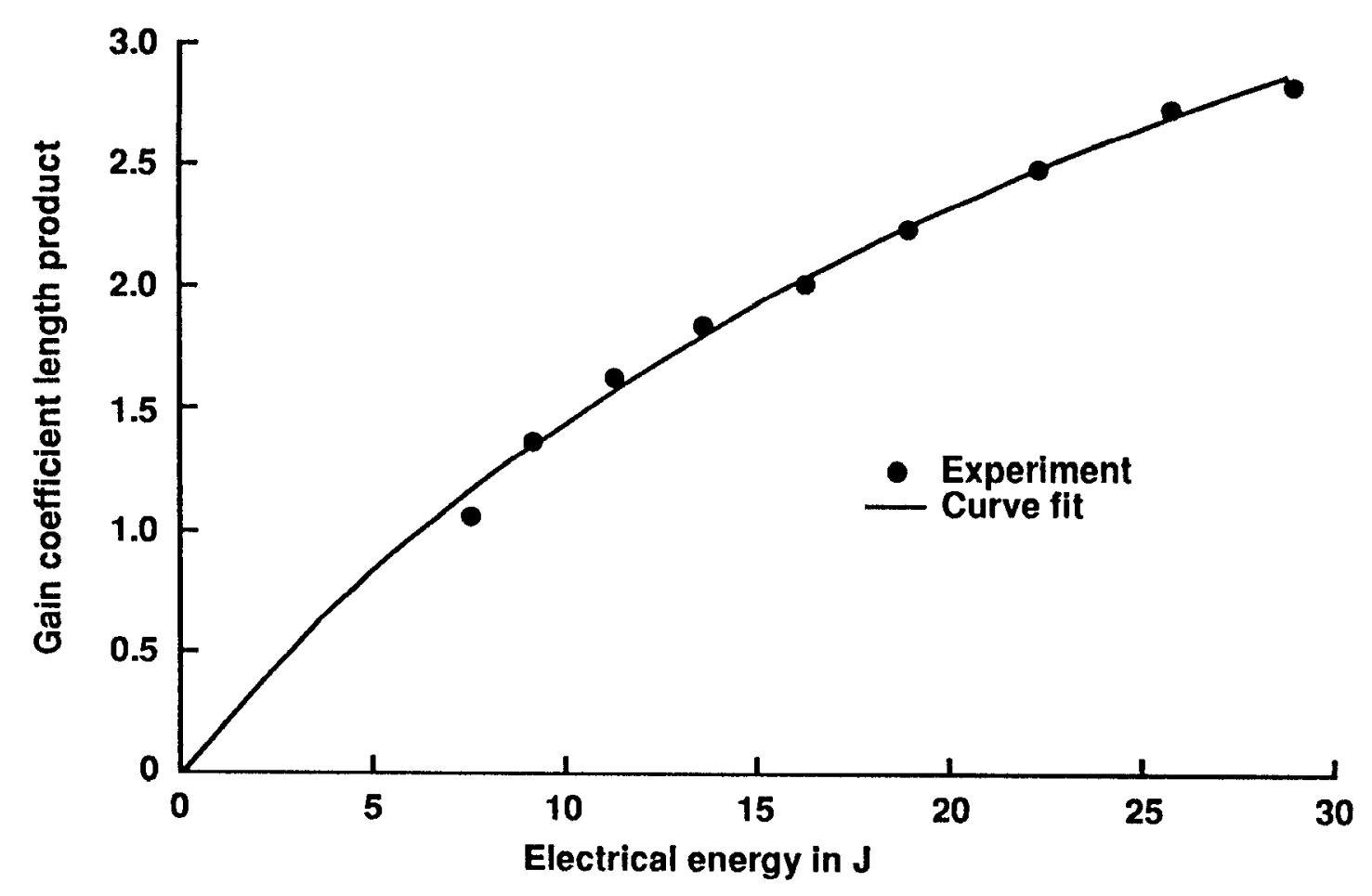

Decay of $\mathrm{Nd}^{4} \mathrm{~F}_{3 / 2}$ Manifold Population

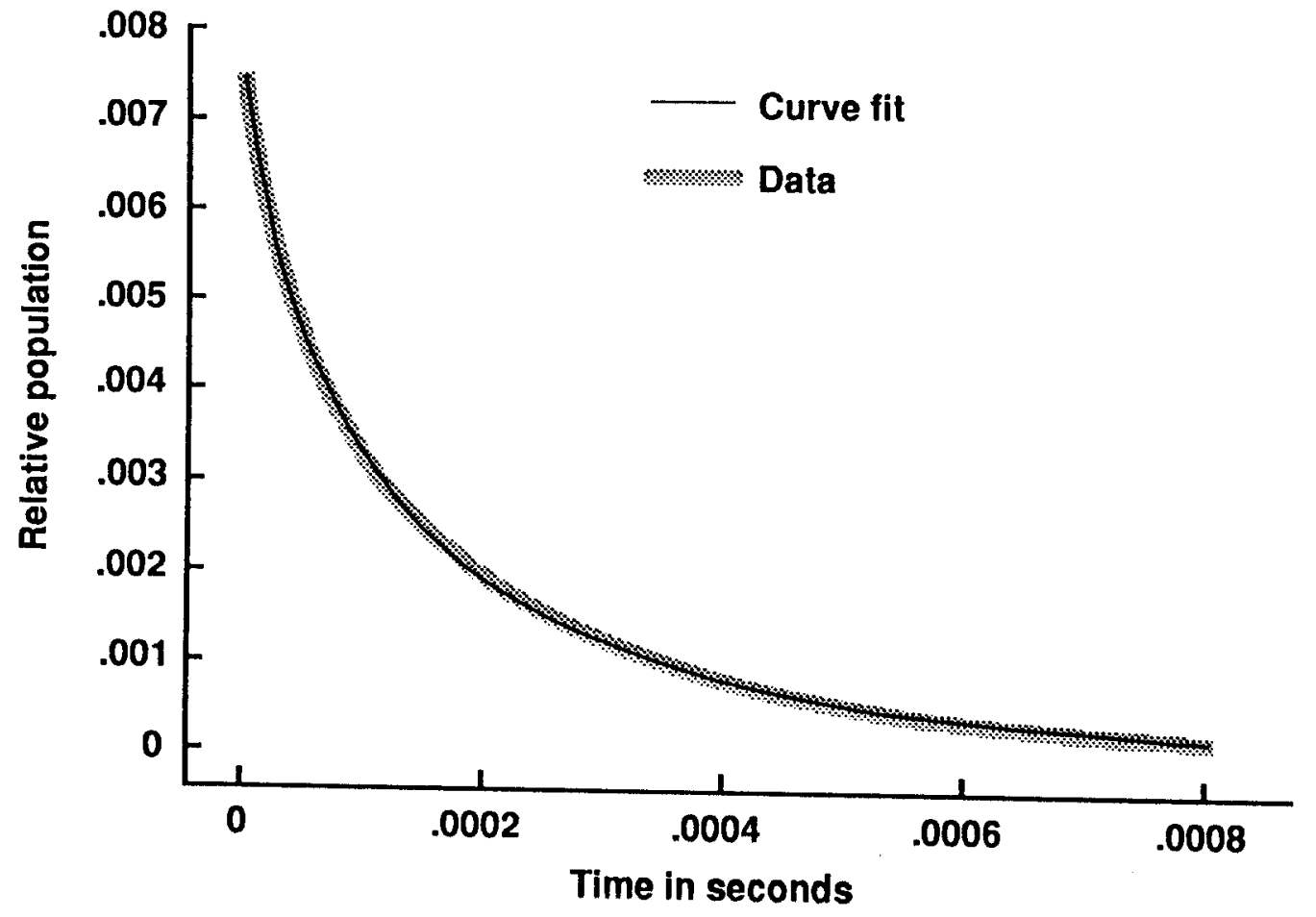

